\title{
LOSING MY CODE: AN AUTOETHNOGRAPHY ON LANGUAGE ATTRITION
}

\author{
Jayrome Lleva Núñez
}

Master in Language Teaching, Visayas State University, Leyte, Philippines

Corresponding Author Email: jayromenunez@teachers.org

\begin{tabular}{|c|c|}
\hline Article Info & Abstract \\
\hline $\begin{array}{l}\text { Article History } \\
\text { Received: August } 2021 \\
\text { Revised: September } 2021 \\
\text { Published: October } 2021\end{array}$ & $\begin{array}{l}\text { Learning a new language is one of the privileges that a person can get when } \\
\text { moving from one place to another and staying there for a longer time. In this } \\
\text { paper, I will discuss my journey that resulted to gradual decline of my LI (First } \\
\text { language), Polillohing Tagalog, which is a variety of the Tagalog language, in }\end{array}$ \\
\hline $\begin{array}{l}\text { Keywords } \\
\text { Sociolinguistics; } \\
\text { Autoethnography; } \\
\text { Language Attrition; }\end{array}$ & $\begin{array}{l}\text { the Philippines. The result of migration, acquisition of other languages, and } \\
\text { exposure to different speaking environment had led me to continuously decline } \\
\text { my first language. Using the auto-ethnographic type of writing a research, I } \\
\text { reflected on my experiences which lead me to language attrition. Auto- } \\
\text { ethnographic research is when the researcher is the participant of the story } \\
\text { narrating his experience on the culture and phenomenon of the researched topic. }\end{array}$ \\
\hline
\end{tabular}

How to cite: Nunez, J. L. (2021). Losing My Code: An Autoethnography on Language Attrition, JOLLT Journal of Languages and Language Teaching, 9(4), pp. 480-487. DOI: https://doi.org/10.33394/jollt.v\%vi\%i.4003

\section{INTRODUCTION}

In the research of language, much effort is devoted to the acquisition of foreign language skills, but little is known about their rate of attrition (Bahrick, 1984). Schools have implemented rules to allow L2 (second language) to flourish in the school grounds. A plethora of teaching strategies have been laid out in order to let learners acquire the new language in the most efficient way. However, it is less known how language acquisition can also affect the first language of any learner.

Speakers who live in an L2 environment for an extended period of time often experience change in the way in which they use their L1, a process referred to as L1 attrition (Schmid, 2013). Majority of work on attrition has been concerned with migrant communities, usually characterized by diminished use of the L1, separation from the L1-speaking community, low degree of acculturation, and a low level of L2 attainment at least in the first generation (Tsimpli, Sorace, Heycock, \& Filiaci, 2004). The availability or lack thereof of the other language community, opportunities to use the language, perceived need of the language, and a host of other variables relating to intergroup interaction and language behavior could influence the amount of language attrition, and the variables that might relate to it (Gardner, Lalonde, Moorcroft, \& Guelph, 1987).

According to Park (2018), there are several factors that need to be taken into consideration when understanding the language attrition phenomenon. In the Park's study, these variables are linguistic and extralinguistic. Linguistic variables (Olshtain, 1989) are considered as input variable that may directly affect the attrition. Meanwhile, extralinguistic variables, according to Park (2018) refer to other elements that influence the rate and quality of attrition, including the attriter's age at the start of attrition, their attitudes and motivation, their literacy in the attriting language, and many others. 
In the history of research on language loss, a vast collection of confusing definitions of the different processes and their results have been used. In order not to complicate matters, the term 'loss' will be used here as the overall term for all types of decline of linguistic skills in individuals. 'Shift' denotes the loss of linguistic skills between generations, while 'attrition' refers to loss of skills in individuals over time (de Bot \& Weltens, 1995). Basically, language attrition is the reverse process of language acquisition (Wei, 2014).

Compared to research on language acquisition, research on the maintenance and loss of language skills is a relatively recent development. The work in the field of attrition started in the USA in the late 70s, and since then research on this field has steadily growing in different countries (de Bot \& Weltens, 1995).

\section{RESEARCH METHOD}

\section{Research Design}

In this research, I will use the auto-ethnographic type of study. According to Wall (2006), autoethnography is an emerging qualitative research method that allows the author to write in a highly personalized style, drawing on his or her experience to extend understanding about a societal phenomenon. Autoethnography is grounded in postmodern philosophy and is linked to growing debate about reflexivity and voice in social research.

It is an approach to research and writing that seeks to interpret and systematically analyze (graphy) personal experience (auto) in order to understand cultural experience (ethno). This approach challenges canonical ways of doing research and representing others and treats research as a political, socially-just and socially-conscious act (Ellis, Adams, \& Brochner, 2011). The idea of the individual/self-identity is the most basic unit of culture (Hamdan, 2012).

In an autoethnographic research written by Ho (2017), she mentioned that the earliest use of the term autoethnography can be traced back to anthropologist David Hayano (1979) in his essay Auto-Ethnography: Paradigms, Problems, and Prospects. In Hayano's essay he proposes that individuals who study people, culture, and societal phenomena, such as anthropologists, to write and do ethnographies of their "own people". In conceptualizing the term, Hayano expresses three reasons why he believes there has been a turn towards autoethnography within schools of anthropology in the United Kingdom and United Stated of America.

First, Hayano (1979) mentions how it has become almost impossible to study "small, isolated tribal groups as if they existed apart from other peoples or world economic and political forces". Second, Hayano saw that a greater number of minority and foreign anthropologists were being trained and that many of them, either by choice or restriction or mandatory, chose to study their own communities and people. Hayano also notes that since there was a growing popularity for courses which studied ethnicity and minority cultures, the need for minority social scientists to study their "own people" grew. Third, Hayano acknowledges that due to a decrease in funding social science research and an increase in competition for funding that supports research aboard had diminished significantly. Consequently, many graduate and postgraduate students in the field of the social sciences found themselves doing some of their "predoctoral or masteral fieldwork in their own backyards" and using their "own people" as a subject of research.

As a method, Ellis, Adams, \& Brochner, (2011) mentioned that autoethnography combines characteristics of autobiography and ethnography. When writing an autobiography, the author retroactively and selectively writes about past experiences. Usually, the author does not live through these experiences solely to make them part of a published document; rather, these experiences are collected using hindsight. Ethnography authors study a culture's relational practices, common values and beliefs, and shared experiences for the purpose of 
helping insiders (cultural members) and outsiders (cultural strangers) better realize the culture. Ethnographers do this by becoming participant observers in the culture (Roulston, 2018) - that is, by taking field notes of cultural actions as well as their part in and others' engagement with these happenings.

Autoethnography challenges canonical ways of doing research and representing others and treats research as a political (Hamdan, 2012), socially-just and socially-conscious act. The researcher uses tenets of autobiography and ethnography to do and write autoethnography. Thus, as a method, autoethnography is both process and a product. Similarly, Wall (2006) mentioned that the emergence of autoethnography as a method of inquiry moves researchers' use of self-observation as part of the situation studied to self-introspection or self-ethnography as legitimate focus of study in and of itself.

This type of study method is seemed to fit as it promotes investigating personal experience, as well as how the person interacts with culture (Henrich, 2012). In this study, I am interested in reexploring my journey of language and codes exposure that may have led to the decline of my first language (L1). While I understand that every school may have different notions about autoethnography, the introspection and evaluation provided by the methodology of autoethnography greatly facilitates an understanding of the processes of culture and phenomenon (Dethloff, 2005).

\section{Sampling and Participant}

This is an autoethnography of my own experience in the researched topic, which is the attrition of L1. I am an overseas Filipino for more than six years, working in the western Asia where Gulf Arabic is the dominant language. I teach technical and vocational courses from people all around the world. However, my classes are dominated by south Asian, who speak primarily Hindi. And Arabs who speak Gulf Arabic. However, before coming here (West Asia), I lived in the northern Philippines (Ilocos Sur) for six years, which primarily speak Yloco as their first language. I also lived in greater Manila area and taught English to Korean learners.

Since this study is an autoethnography, I am utilizing my personal endeavor on the researched topic in order for the readers to witness the phenomenon. There is no term yet utilized for auto-narrative studies - thus, I will use what Vasquez (2013) coined in one of his studies, "autosampling". According to Vasquez (2013), this defines purposely to the domain of the researcher himself with substantial experience to the context being researched, thus $\mathrm{n}=1$. Currently, I am a graduate student at Visayas State University taking up Masters in Language Teaching.

\section{Data Collection}

The method used in this type of research is descriptive/self-affirmative (Roulston, 2018), wherein I describe my journey in the culture of language that led me to gradually lose my first code. As auto-ethnography, the techniques I use are the Personal Narratives and Layered Accounts types of autoethnography. According to Ellis, Adams, and Brochner (2011), layered accounts often focus on the author's experience alongside data and relevant literature. This form emphasizes the procedural nature of research. While personal narratives are stories about authors who view themselves as the phenomenon and write evocative narratives specifically focused on their academic, research, and personal lives. This research answers two critical questions: (1) What led me to lose my first language (a variant of Tagalog)?; and (2) What steps do I take in order to re-acquire or at least retain my knowledge in the language? 


\section{RESEARCH FINDINGS AND DISCUSSION}

\section{First Language Background}

I grew up in Polillo Island, Quezon Province. It is situated on the eastern part of Luzon in Region IV-A. This region is also known as the Southern Tagalog Region. It is where many varieties of Tagalog language are being spoken and one of them is the Tayabas Tagalog (Manuel, 1909). Compared to the popular Manileñong Tagalog or Batangas Tagalog, Tayabas or Quezon Tagalog has more on falling intonation, same as our Polillohing Tagalog. Growing up with our own variety of the Tagalog language was authenticating our existence in the island. Only we can speak and understood it. When someone moves or travel to the mainland, we basically have to leave our code to our island and use the Manileñong Tagalog in order to communicate with the people outside our island. I was used to our Polillohing Tagalog for a very long until I graduated high school in 2005.

As I grow older and away from my home town, the L1 I grew up has become so distant to me that I rarely even practice it. In my video calls with my parents, who live in our hometown, I couldn't help but use the Manileñong Tagalog because I can hardly use our language. The manners and cues locally used seemed difficult for me to put into context. Example: To us, the use of "kasi" in a sentence is one of the most awkward moments during a discourse with a local. It sounds so "Manila", we don't use it in our locality. Example: In Metro Manila, they would say, "Ang hirap kasi nung test, kaya ako bumagsak!" (The test was difficult, that's why I failed). In our code, we say it like: "Ay hirap ta naman nong test ay, paanong hindi babagsak?" (The test was difficult; how could I pass?). While I (attriter) may fully comprehend terms and linguistic forms when exposed to them in context, I find it difficult in producing the same manner (Olshtain, 1989).

The variant of Tagalog we have may differ to the many of Tagalog speakers speak. They may have different meaning on the way they use it in the sentence. Look at the Facebook post I made in 2016 to honor and remember the language I am slowly losing. The post collectively got 4.4 thousand shares and more than five thousand collective likes. Here's the post.

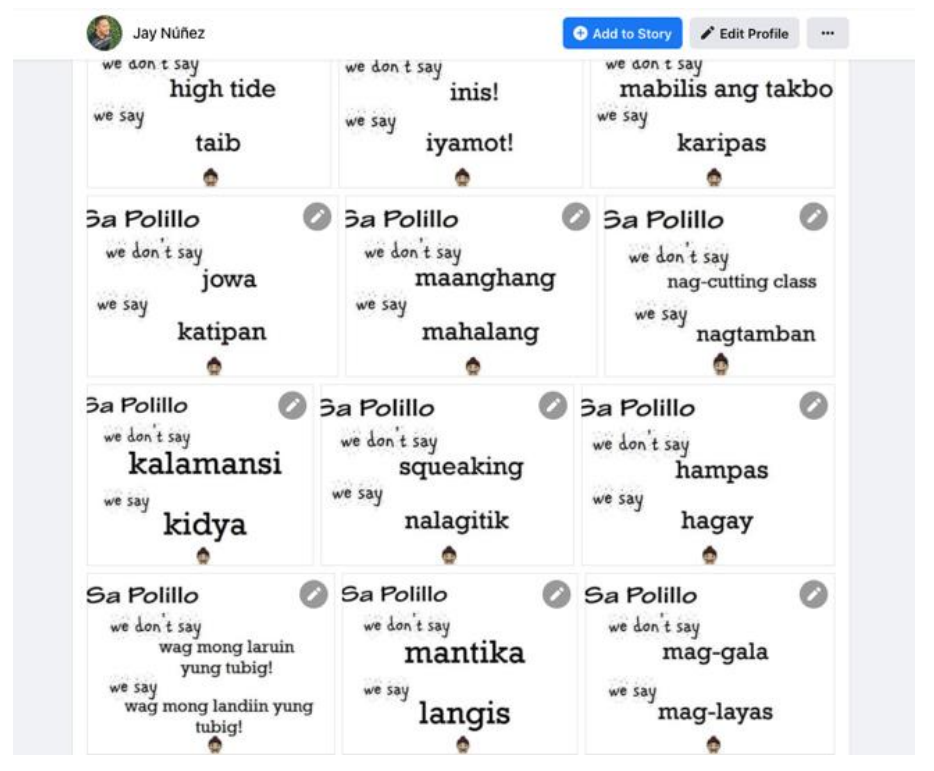

Image 1. Screenshot of the Facebook post to show differences of our Tagalog variant. (Source: https://www.facebook.com/media/set/?set=a.10208158084651578\&type=3)

Some words or phrases in standardized Filipino may have a different word for us, example: "Malakas ang ulan" (heavy rain or downpour), to us, we say, in one word as: "lurok". For "kargador" (shipper, someone who works in pier), we call them "hornal". There 
are many words that I have forgotten and I could not identify them anymore unless I immerse myself again in our town

\section{The Yloco (Ilocano) Language}

According to Republic Act of the Philippines (R.A.) 7104, Section 3 or the Commission on Filipino Language Act, Ilocano language is one of the eight major languages and third major tongue spoken in Philippine archipelago (Shofner, 2008), it is mainly used in the northern region, one of which is Ilocos Sur. Ilocano or Iluko or Yloco, one referred to as the "national language of the north" for its prominence in that hemisphere (Rubino, 1998), is the chief regional language of Northern Luzon.

It is used by at least twenty million (Shofner, 2008) native speakers in the Philippines. It ranks third, after Cebuano and Tagalog in number of native speakers, and is the language of the group of provinces originally referred to as the Ilocos Region (Ilocos Norte, Ilocos Sur, La Union, and Abra). It is also widely spoken in the provinces of Isabela, Pangasinan, Tarlac, Zambales, Nueva Vizcaya, and Nueva Ecija. In addition, it is the lingua franca of all the mountain provinces of Luzon. Speakers are also numerous in the towns of Occidental Mindoro and Oriental Mindoro. In the southern island of Mindanao, large enclaves of Ilokano speakers are found in Cotabato and Davao. In Manila, it is not usually nowadays to hear Ilokano spoken in public places (University of Hawai'i at Manoa).

When I got a scholarship to one of the most prestigious Catholic private institutions in the Philippines, I had option to choose among the different schools from Vigan (Ilocos Sur), Dumaguete (Negros Oriental), Iloilo (Iloilo), and Surigao (Surigao del Norte). Metro Manila campuses were fully occupied and could not accommodate me anymore leaving me with the provincial options. Had not they been full, I could have stayed nearer to home. With that, I chose Ilocos Sur because it is in the mainland of Luzon, however it is more than 12 hours away from where I came from. For six years, I was able to assimilate Yloco language while using the Manileñong Tagalog. Yloco Vigan has become my third language (L3) after English as L2. During all my stay in Ilocos Sur, I rarely use the variant of Tagalog I grew up from. L3, according to Hammarberg (2018) refers to a non-native language which is currently being used or acquired in a situation where the person already has knowledge of one or more L $2 \mathrm{~s}$ in addition to one or more L1s.

After the first few years of stay in the northern province, during my vacation at my parents' I observed that I am forgetting some indigenous words I used to speak growing up. Words, expressions, and tone were Yloco were mixed on my speaking. My parents had even noticed the change of my tone. The longer I stayed in Ilocos, the more I became a near-native in speaking the language. For six years, my friends and I have noticed how my speaking have fully adapted to the locality. I was even able to copy different ayog or accents of different towns in the province. As a migrant in the region, I achieved high level of proficiency (Schmid, 2013) in the local language of my environment as I use it in my daily routine. I even had times delivering readings in Ilocano during Eucharistic Mass. Until I left Ilocos and moved to Manila.

\section{Manileñong Tagalog (Manila-variant of Tagalog)}

When I left Ilocos, one of the best take-aways I had was the gift of language. Learning the language opened up a lot of unforgettable experiences about the reagion's culture which I would have not experienced if I didn't know the language. It is a fact that language opens up a whole new lifetime experience. And that happened happened to me. Consequently, in order for me to grow my career I moved to the country's capital. There, I landed in different call center jobs, met different people from all over the country, and used the Manileñong Tagalog every day of my life. As we all know, Manileñong Tagalog is informally known as the conyo or English-fied way speaking Tagalog. 
Taglish or Tagalog-English is a manner of speaking the language with code switching from English to Tagalog at the middle of sentences. The use of an item from the L2 in the L1, often in such a way that it is integrated phonologically and/or morphologically (Schmid, 2013). Example: "Magte-test dahil naka-schedule yung finals". This phenomenon does not only happen in Filipino but other languages too like, Hindi (Hinglish) or Spanish (Spanglish). After my call center hopping, I applied in an English academy to teach Koreans online. We had training for neutralization of our English. One of the comments I got from the trainer was I had a very heavy Ilocano accent when I speak English. I had to go to series of training in order to neutralize it before putting me on the floor.

After the intense training, my English has been neutralized and they allowed to be on the floor to teach our learners. It was my day-to-day routine. I did not use Yloco or our Polillohing Tagalog in any of my discourse because most of my coworkers are locals of the Metropolitan Manila. Even with my roommates, they were from Tarlac and Pangasinan. On my stay in online teaching Koreans, I also had sidelines of teaching the same people offline or face-to-face. So, I had to speak the target language in most of my days at work.

\section{Being an OFW (Overseas Filipino Worker)}

When I left Manila in 2015 and moved in Saudi Arabia to work as English language teacher, that is when the language mixed up started. As I stay with many locals (Saudi) every day, I assimilated their language (parts), tone, and manner of speaking. They are so attached to their first language (Arabic) that speaking to them in straight English would leave them stunned, so I had to use the English-carabao version of speaking. English carabao is a form of Filipino conversational English riddled with grammar boo-boos or gaffe (The Filipino Times, 2019). During my teaching days with these Saudis, I hardly remember that I spoke to them in good grammar or straight English. My English had not been this broken whenever I converse with them.

After three years, I got transferred to another project. Here, I handle peoples of the world. They come from different nations (India, Pakistan, Nepal, Malaysia, Indonesia, USA, Mexico, Russia, Philippines, Colombia, Ghana, Saudi, Egypt, Yemen, and many more), with different language backgrounds. Until now, I am in this department and just using English all the time with my conversation. Apparently, because most of my learners are south Asian (India, Pakistan, Nepal, Bangladesh), I have adapted to the manner they use the language and the accent. We speak the Pidgin Arabic (Al Ghamdi, 2014) if my trainee does not understand English very well. In my entire stay stay here in Saudi Arabia until now, I rarely use the Ilocano language and my Polillohing Tagalog.

\section{Losing the codes}

As I live farther from my home town, I could barely use my first code and Ilocano language. It makes me upset because inasmuch as I want to practice my first language and Ilocano language, I will need another person to use it with. There is nothing I can do to make the situation better in my ability with the languages.

The situation is also the same with my Egyptian co-teacher here, during our talk he mentioned that in his prime years his English was better. He was in B2 level when he moved here in Saudi Arabia to teach. Since the change of language environment (Park, 2018), his English has deteriorated much that now he can barely speak it anymore. He mentioned that the L2 was never used in his entire two decades of stay here in the gulf reducing it to the very minimum.

In my situation, I think losing my first language will take years to completely remove it from my system, however the Ilocano language which I only acquired through assimilation will be easily lost by just few years should there be no chance for me to practice it. And that is 
seconded by a research by Park (2018) that mentions, oral fluency is highly susceptible to attrition.

\section{Future Plan}

Language attrition of both my first code and Ilocano languages, will, I think worsen because of my future plans in migrating to another country where English is not the main language spoken. Right now, I am enrolled in learning Spanish as my partner demands it to me that I need to be able to have a conversational Spanish when I move. As I acquire new language, another will be shelved and will not be used for a long time.

\section{CONCLUSIONS AND RECOMMENDATIONS}

Language attrition is an inevitable circumstance due to the fact people move or migrate. There will always be something that we will lose along the way as we acquire new knowledge, skills, and language, to name a few. While this auto-ethnography is written as a narrative of the researcher experiencing the phenomenon of language attrition, it is important to take note that this research is part of witnessing and representing others in the same phenomenon (Ellis, Adams, \& Bochner, 2010). Consistent with the literature, it is important that we also hear the story behind the phenomenon so the participants will not just be part of the statistics, hence qualitative research. This narrative is written to raise awareness on language attrition specially in places like Philippines which is linguistically diverse and people speak more than one language which can be prone to attrition as we acquire new language when we to another region or country. There is only one way to retain a language that I could recommend upon in-depth recalling the events that happened to me resulting to losing them, and that is practicing it and staying at the place where it is widely or commonly used.

\section{REFERENCES}

Al Ghamdi, E. A. (2014). Gulf Pidgin Arabic: A Descriptive and Statistical Analysis of Stability. International Journal of Linguistics. DOI: 10.5296/ijl.v6i6.6846

Bahrick, H. P. (1984) Fifty Years of Second Language Attrition: Implications for Programmatic Research. The Modern Language Journal. 68(2), 105. doi:10.2307/327136

De Bot, K., and Weltens, B. (2008). Foreign Language Attrition. Annual Review of Applied Linguistics. 15, 151. doi:10.1017/s026719050000266x

Dethloff, C. H. (2005). A Principal in Transition: An Autoethnography. Unpublished dissertation. Texas A\&M University, College Station, Texas, USA.

Ellis, C., Adams, T. E., and Bochner, A. P. (2011). Autoethnography: An Overview [40 paragraphs], Forum Qualitative Sozialforschung / Forum: Qualitative Social Research. 12(1), Art. 10, http://nbn-resolving.de/urn:nbn:de:0114-fqs1101108

Gardner, R. C., Lalonde, R. N., Moorcroft, R., \& Evers, F. T. (1987). Second Language Attrition: The Role of Motivation and Use. Journal of Language and Social Psychology, 6(1), 29-47. doi:10.1177/0261927x8700600102

Hammarberg, B. (2018). L3, the tertiary language. In Foreign Language Education in Multilingual Classrooms, A. Bonnet \& P. Siemund (eds.), 127-150. Amsterdam/Philadelphia: John Benjamins.

Hamdan, A. (2012). Autoethnography as a Genre of Qualitative Research: A Journey Inside Out. International Journal of Qualitative Methods. University of Alberta, Canada.

Henrich, K. (2012). Towards Integration: An Autoethnography on the Development of Identity. Unpublished master's thesis. Columbia College Chicago, Chicago, Illinois, USA. 
Ho, Michael Duy-Tran. (2017). It is you that I see in me: an autoethnographic exploration of the artist teacher identity. Unpublished master's thesis. University of Illinois at UrbanaChampaign, Illinois, USA.

Manuel, A. E. (1909). Book. A lexicographic study of Tayabas Tagalog of Quezon Province.

Olshtain, E. (1989). Is Second Language Attrition The Reversal Of Second Language Acquisition? Cambridge University Press. Tel Aviv University, Israel

Park, E. S. (2018). Language Attrition. The TESOL Encyclopedia of English Language Teaching, First Edition. DOI: 10.1002/9781118784235.eelt0843

Roulston, K. (2018). What is Autoethnography? QualPage, Examining the world through qualitative inquiry.

Rubino, Carl. 1998. Ilocano Phrasebook and Dictionary. New York: Hippocrene Books. Ilocano Grammar and Dictionary. Honolulu: University of Hawaii Press.

Shofner, K. (2008). Understanding the difference between Tagalog and Ilocano. Retrieved fromhttps://www.unitedlanguagegroup.com/blog/translation/ilocano-tagalogdifferences

Schmid, M. S. (2013). First language attrition. Wiley Interdisciplinary Reviews: Cognitive Science, 4(2), 117-123. doi:10.1002/wcs.1218

The Filipino Times. (2019). 'English Carabao' - Grammar boo-boos become an obsession for humor. https://filipinotimes.net/feature/2019/07/07/english-carabao-grammar-boo-boosbecomes-obsession-humor/

Tsimpli, I., Sorace, A., Heycock, C., \& Filiaci, F. (2004). First language attrition and syntactic subjects: A study of Greek and Italian near-native speakers of English. International Journal of Bilingualism, 8(3), 257-277. doi:10.1177/13670069040080030601

University of Hawai'i at Manoa. (n.d.). Ilokano Language Literature Program. Retrieved from http://manoa.hawaii.edu/ilokano/mission.html

Vasquez, B. A. (2013). Politico-economic influence and social outcome of English language among Filipinos: An autoethnography. University of the Visayas - Journal of Research, 7(1), 183-194

Wall, S. (2006). An Autoethnography on Learning About Autoethnography. International Journal of Qualitative Methods. University of Alberta, Canada. doi:10.1177/160940690600500205

Wei, J. (2014). Selectivity of Second Language Attrition. Theory and Practice in Language Studies, Vol. 4, No. 8, pp. 1603-1608. doi:10.4304/tpls.4.8.1603-1608 